\title{
Multi-Drug Therapy Schedules for SARS-COV-2: Smart Repurposing of Old Drugs
}

\author{
Ahmed B. Bayoumy ${ }^{1 *}$, Azhar R. Ansari², Ronney A. De Abreu ${ }^{2}$, \\ Godefridus J. Peters ${ }^{3,4}$ and Chris J.J. Mulder ${ }^{5}$ \\ ${ }^{1}$ Faculty of Medicine, Amsterdam UMC, University of Amsterdam, the Netherlands: ${ }^{2}$ Independent scholar; ${ }^{3}$ Department of Medical Oncol- \\ ogy, Cancer Center Amsterdam, Amsterdam UMC, locatie VUmc, the Netherlands; ${ }^{4}$ Department of Biochemistry, Medical University of \\ Gdańsk, Poland; ${ }^{5}$ Department of Gastroenterology and Hepatology, Amsterdam UMC, locatie VUmc, the Netherlands
}

We want to comment on the article by Swaim et al. ${ }^{1}$ that was recently written. They reported findings characterizing thioguanine (TG) as an inhibitor of the papain-like protease (PLpro). The PLpro protein has been shown to be of significant importance in the replication process of severe acute respiratory syndrome coronavirus (SARS-COV-2). Inhibition of this protease by TG can halt viral replication. ${ }^{1}$ TG and methotrexate (MTX) are known inhibitors of viral de novo purine synthesis. The combination of both drugs could theoretically provide strong inhibition against viral RNA and DNA synthesis. ${ }^{2}$ Also, the cytidine analog 5-azacytidine (commonly known as 5-AZC) can lead to incorporation of false residues, thereby inhibiting viral RNA transcription. ${ }^{3}$ A triple therapy of these three agents might be a promising strategy for treatment of SARS-COV-2.

Another drug that has already been registered for severe SARS-COV-2 cases is remdesivir, which is known to inhibit the SARS-COV-2 RNA polymerase. Remdesivir is a prodrug and is incorporated in the viral RNA more efficiently than ATP, leading to chain-termination. ${ }^{4} \mathrm{TG}$ is considered to have a different mechanism, thus making the possibility of a synergistic therapeutic action more likely. Multiple antivirals can be combined to maximize efficacy and prevent viral resistance due to mutations. This approach has proven very successful in treatment of patients with human immunodeficiency virus infection with highly-active antiretroviral therapy. ${ }^{5}$ Different antiviral therapies have been proposed as having potential efficacy for SARS-COV-2. ${ }^{6}$ Hence, an approach of combining TG with other therapies (e.g., MTX, remdesivir, and others) could provide inhibition of different target sites in the viral replication process. Such a multidrug therapeutic approach could be very effective in tackling SARS-COV-2.

Another effect of TG is the reduction of pro-inflammatory cytokine production from immune cells. ${ }^{1}$ SARS-COV-2 has been associated with hemophagocytic lymphohistiocytosis syndrome and cytokine storms, which can lead to severe respiratory insufficiency and a hypercoagulative state. This condition is also known as the COVID-19-associated coagulopathy (commonly referred to as

Abbreviations: TG, thioguanine; SARS-COV-2, severe acute respiratory syndrome coronavirus; MTX, methotrexate; 5-AZC, 5-azacytidine; CAG, COVID-19-associated coagulopathy.

Received: August 03, 2020; Accepted: August 10, 2020

${ }^{*}$ Correspondence to: Ahmed B. Bayoumy, Faculty of Medicine, Amsterdam UMC University of Amsterdam, the Netherlands. Tel: +31-205-665-072, Fax: +31-020-6912401, E-mail: a.b.bayoumy@amsterdamumc.n1

How to cite this article: Bayoumy AB, Ansari AR, De Abreu RA, Peters GJ, Mulder CJJ. Multi-Drug Therapy Schedules for SARS-COV-2: Smart Repurposing of Old Drugs. J Explor Res Pharmacol 2020;5(3):29-30. doi: 10.14218/JERP.2020.00022.
CAG). ${ }^{7}$ TG can, therefore, potentially prevent severe complications of SARS-COV-2, like CAG and multiorgan failure. ${ }^{7}$ Dexamethasone has also been used with anticoagulant therapy to reduce these complications of SARS-COV-2. Hence, dexamethasone and anticoagulants can be combined with a multi-drug therapy regimen for SARS-COV-2.

TG has been shown to be a dose-dependent inhibitor of PLpro and therefore the correct dosage of TG is very important. Swaim et $a l .{ }^{1}$ referred to leukemia dosages ( $\geq 3 \mathrm{mg} / \mathrm{kg} /$ day) of TG for the treatment of SARS-COV-2 and reasoned that due to the short time period the level of toxicity would be minimal. However, these high dosages have been known to induce pancytopenia and to be less tolerated by patients. ${ }^{8}$ We believe TG should be initiated at $1 \mathrm{mg} / \mathrm{kg} /$ day upon hospitalization for the first 3 days, then $0.6 \mathrm{mg} / \mathrm{kg} /$ day for the next 3 days and lowered to $0.3 \mathrm{mg} / \mathrm{kg} /$ day for remaining treatment till discharge. This would reduce the amount of side-effects and could be an effective treatment. MTX could be initiated at $25 \mathrm{mg}$ in the first week and then the remaining dose should be $15 \mathrm{mg}$ weekly.

In conclusion, TG seems to be a high-potential drug for the treatment of SARS-COV-2. It has been used for a range of diseases in the past, such as leukemia and inflammatory bowel disease, and can be repurposed for other diseases, such as SARS-COV-2 ${ }^{8}$ TG can also be combined with other drugs (e.g., MTX, remdesivir, and antivirals) to achieve maximal benefit for severely affected SARSCOV-2 patients.

\section{Acknowledgments}

None.

Funding

None.

Conflict of interest

The authors declare that they have no conflicts of interest.

Author contributions

$\mathrm{AB}$ and $\mathrm{AA}$ were responsible for the conceptualization of the man- 
J Explor Res Pharmacol

uscript. $\mathrm{AB}$ was responsible for the writing of the original draft. All authors were responsible for writing, reviewing and editing of the manuscript.

\section{References}

[1] Swaim CD, Perng YC, Zhao X, Canadeo LA, Harastani HH, Darling $T L$, et al. 6-Thioguanine blocks SARS-CoV-2 replication by inhibition of PLpro protease activities. bioRxiv 2020:183020. doi:10.1101/2020.07.01.183020.

[2] De Abreu RA, Lang HRM. A proposal for triple treatment of SARSCoV-2 with Methotrexate, 6-thioguanine and cytosine arabinoside. ResearchGate (Preprint) 2020. doi:10.13140/RG.2.2.30019.55841/1.

[3] Li LH, Olin EJ, Buskirk HH, Reineke LM. Cytotoxicity and mode of action of 5-azacytidine on L1210 leukemia. Cancer Res 1970;30(11):2760-
Bayoumy AB. et al: Multi-Drug Therapy Schedules for SARS-COV-2

2769.

[4] Gordon CJ, Tchesnokov EP, Woolner E, Perry JK, Feng JY, Porter DP, et $a l$. Remdesivir is a direct-acting antiviral that inhibits RNA-dependent RNA polymerase from severe acute respiratory syndrome coronavirus 2 with high potency. J Biol Chem 2020;295(20):6785-6797. doi:10.1074/jbc.RA120.013679.

[5] Arts EJ, Hazuda DJ. HIV-1 antiretroviral drug therapy. Cold Spring Harb Perspect Med 2012;2(4):a007161. doi:10.1101/cshperspect.a007161.

[6] Şimşek Yavuz S, Ünal S. Antiviral treatment of COVID-19. Turk J Med Sci 2020;50(SI-1):611-619. doi:10.3906/sag-2004-145.

[7] Iba T, Levy JH, Connors JM, Warkentin TE, Thachil J, Levi M. The unique characteristics of COVID-19 coagulopathy. Crit Care 2020;24(1):360. doi:10.1186/s13054-020-03077-0.

[8] Bayoumy AB, Simsek M, Seinen ML, Mulder CJJ, Ansari A, Peters GJ, et al. The continuous rediscovery and the benefit-risk ratio of thioguanine, a comprehensive review. Expert Opin Drug Metab Toxicol 2020;16(2):111-123. doi:10.1080/17425255.2020.1719996. 